\title{
DESIGN AND FABRICATION OF AN AUTOMATIC GARBAGE COMPRESSOR FOR INDIAN RAILWAYS: USING PRINCIPLES OF ELECTRO-PNEUMATIC AND CONTROL THEORY
}

\author{
Rhea Mehra \\ Department of Automobile Engg \\ Manipal Institute of Technology, Manipal, Karnataka, India
}

\author{
Vrinnda Gupta \\ Department of Automobile Engg \\ Manipal Institute of Technology, Manipal, Karnataka
}

\begin{abstract}
Trains are one of the most common modes of transport in India. They provide employment to 1.54 million people according to the recent statistics [1]. The aim of this paper is to shed some light on the matter of waste management and disposal on trains. Ranjan et al. (2016) wrote in India Today, that Indian Railways generate around 10-15 tons of garbage on major stations every single day [2]. This number is not only appalling but also quite dangerous to the society and the environment. To contribute to the above issue and to ease the pain of hard working laborers in the Railway sector, automation is extremely important. Highly advanced countries like China and Japan have worked hard to bring about huge changes in their sanitation, waste management and quality in the past decade. Hence, this paper pivots around the function, application and implication of an Automatic Garbage Compressor which has been meticulously designed for a safe, modern and hygienic method of garbage disposal using Control Systems and Simulation. The Automatic Garbage Compressor consists of an electro-pneumatic compressor which functions automatically to compress the overflowing garbage in the dustbin $(60 \mathrm{~cm} \times 40 \mathrm{~cm})$ to its minimal size, repeatedly until it has to be disposed of. This allows a considerable delay in garbage disposal which makes it convenient for the workers. It is equipped with an emergency stop button and is essentially a fully automatic mechanism. The piston detects the level of garbage with the assistance of a shortrange reed switch. This, in turn, activates the piston which further compresses the garbage for about 30 seconds. The piston then returns to the initial position which makes space for more garbage intake. The material for the garbage can (Aluminum 6061) and the piston (Sheet Metal) was selected with its correlation to stress-yield range and considering engineering properties like stress analysis, the force exerted by piston, safety and other fabrication processes.
\end{abstract}

Keywords-Control systems, Garbage Compressor, Electro pneumatics, Automatic Compression

\section{INTRODUCTION}

Control Systems refers to commands or a set of logic loops, curated to carry-out a mechanically desired work output. Electro-pneumatics is one such sector which entails the progression of electrically programmed, pneumatic control outputs. An equivalent concept has been formulated as the basis of employing a problem-solving technique in Railways for maintenance of hygiene and garbage disposal.

India, the 2nd fastest developing economy in the world catapulted to world rank of 44th in terms of 'World Digital Competitiveness' in 2019 as compared to 48th in 2018 [3]. Automation is another field which has embedded its roots deep into the technological sphere and opened doors to the future with its unconventional problem-solving techniques.

The Automatic Garbage Compressor (AGC) has been developed to conform to the demands of the people travelling in trains by offering them an opportunity to interact in a more futuristic milieu which is easy to decipher and needs little assistance. The scope of this research is concerning the Indian Railways only. The reason for that is the ever growing need for manual labor who are required to dispose of the garbage at major stations and deposit the collected garbage in the on board dustbins. This served as an incentive to adopt an avant-garde yet sophisticated approach which not only is convenient for the user but also reduces human intervention effectively. It provides a cleaner, safer method of disposing garbage for the passengers as well as the staff. It is the first garbage compressor to be controlled by an electro-pneumatic circuit which makes it all the more efficient and reasonable as compared to hydraulic actuation which is costlier, heavier and exhibits a danger to the people due to frequent fluid leakage. The primary objective of AGC is to serve as a catalyst in the rise of technological advancements as envisioned by the Indian 
Railways. However, a strictly utilitarian purpose served by AGC is to minimize human intervention and maximize convenience.

Automatic Garbage Compressor realizes an efficient means of compressing garbage using principles of electro pneumatics. With an approximate volume of 300 liters, a compaction ratio of 3:1 and a cost estimate of about 6000 rupees (with the equipment), AGC is a huge but necessary investment for the Indian Railways.

\section{Mechanism used to compress garbage in AGC:}

Gawade et al. (2017) employ the use of a PIC microcontroller and a DC motor to develop a Solar Trash Powered Garbage Compactor which reduces pollution and has an LCD screen that displays the current status of the receptacles [10]. Many of these units were employed by the city of Philadelphia in the year 2016, which saw a 70 per cent dip in the cost of transporting and collecting municipal waste according to [10]. The success rate of Solar Trash Powered Garbage Compactor is quite high and it has been successful in reducing waste collection costs. People in Philadelphia are using this technology regularly which also buttresses the claim that people in India might be open to the use of AGC and accept the novel method of waste disposal.

However, a hydraulic setup has been opted to perform the required mechanism. It increases the weight of the bin and also requires frequent maintenance as the fluid leaks and causes hindrance in the operation of the setup. For more information, refer to [10].

While it is important to compare [10] and AGC, it is also important to understand that the Solar Powered Garbage Compactor was built for outdoor usage and AGC will be fitted inside the railway compartment attached to an electrical supply. It is not yet equipped with artificial intelligence but it is certainly economical and purposeful. It has a lower budget which does not necessarily lower its value but rather describes another method of implementing almost the same mechanism as [10] with a relatively uncomplicated yet workable circuit. AGC has not yet made the production line but if it is welcomed into the society by the general public, it can undergo certain technically advanced modifications (application of voice assistance, LCD screens etc.).

The waste compactor designed by Vroom et al. (2016) in their work use bevel gears to compact the waste [11]. Gears not only require manual effort but they also expend energy outside the environment which causes losses while operating and consequently reduces the efficiency. Although the Solid Compactor has to be operated manually, it is significant to highlight it in this research project because it strengthens the idea of employing a fully automatic garbage compressor.

Thus, all three research projects have the same aim, that is to compress garbage to a smaller volume and delay the collection and disposal of the garbage. The mechanisms used to achieve compression are different namely pneumatic, hydraulic and gears which makes it tedious to choose one. Gears are easy to implement but it is a manual compression as opposed to the other two fully automatic ones. Hydraulics is expensive but more efficient than pneumatics. Pneumatics or Electro pneumatics is cheaper to implement, gives optimum efficiency and does not require frequent maintenance. Hence, for this project Electro pneumatics was the prime choice.

\section{The need for AGC in Indian Railways:}

According to [2], the staff members collect the garbage from a single coach and furtively, throw the sack out on the tracks instead of depositing it in the dustbin, which is already ready to be disposed of at the next major station. Thus, if the garbage was being compressed, more space would be made for the rest of the garbage and the disposal can be delayed until the train arrives at a major station.

Gawande (2018), has effectively conducted surveys in the Railway sector regarding the behavior of passengers towards waste disposal [12]. The survey was conducted in four express trains by the researchers of IIM Ahmedabad at Surat Railways station which deduced that, 'almost $80 \%$ of the respondents revealed that there is a need for better provisioning of dustbins within trains [Gawande,2018, p.140]'. The research made a myriad of key observations, for example, the dustbins are often unkempt and overflowing with garbage. It is an unsanitary environment and the waste generated is not closely monitored which in turn fails to comply with the statutory obligations. Secondly, there is an absence of novelty and mechanized approach towards waste management and disposal at smaller stations. Lastly, the current scenario of the Railways as observed by Gawande (2018) is that, there are only two dustbins which allegedly hold the garbage of a single coach and most of the hoi polloi travelling in general class are not even cognizant of the fact that there is a dustbin under the washbasin. For more details on the research, refer to [12].

After extensive research in the domain of automatic/manual garbage compressors and the current scenario of the Indian Railways, it is imperative that people become aware of the significance of waste management and disposal. AGC can be the radical change that the society needs. It can replace mundane dustbins to revolutionize waste disposal and sanitation standards in Railways to a great extent. It is a compelling approach towards achieving a 'Swachh Bharat' (clean India) as envisioned by Narendra Modi, the Prime Minister of India.

\section{METHODOLOGY}

The dimensions of the dustbin, the length and thickness of the piston rod and the diameter of the piston was decided purely with speculation keeping the current garbage disposal used in Indian Railways as the reference. It was then designed on 3D 
Builder by Microsoft, considering certain design parameters which have been elucidated later in the paper. Designing and further modifications of the dustbin provided us with a more tangible view of our project. It improved visual acuity and elicited intricacies which otherwise, would have been overlooked.

\section{A. Specifications:}

Garbage bin dimensions

Piston Rod Length (Stroke)

Piston Bore Diameter $\left(D_{p}\right)$

Piston Rod Diameter $\left(\mathrm{D}_{\mathrm{r}}\right)$

Reed Switch Range [4]

Thickness of Piston plate

Pressure Applied, P

Area of piston $\left(A_{p}\right)$

Area of piston $\operatorname{rod}\left(\mathrm{A}_{\mathrm{r}}\right)$

Yield strength of Aluminum

6061 [5]

Yield strength of grade 3003

H-14 sheet metal [6]

Force applied by the piston

on the garbage $\mathrm{F}_{\text {EXT }}$

\section{$60 \mathrm{~cm} \times 40 \mathrm{~cm}$ \\ $60 \mathrm{~cm}$ \\ $38 \mathrm{~cm}$ \\ $5 \mathrm{~cm}$ \\ $1 \mathrm{~cm}$ \\ $6 \mathrm{~mm}$ \\ 5 bar \\ 0.1133 \\ 0.00196}

$310 \mathrm{MPa}$

$21 \sim 25 \mathrm{MPa}$

$56.65 \mathrm{kN}$

For details refer to the Calculations section of the paper.

\section{B. Hardware:}

Reed Switch (2)

Pressure Regulator

Timer

Emergency Push Button

Double acting cylinder

Two solenoids y1, y2

Relay switch K1

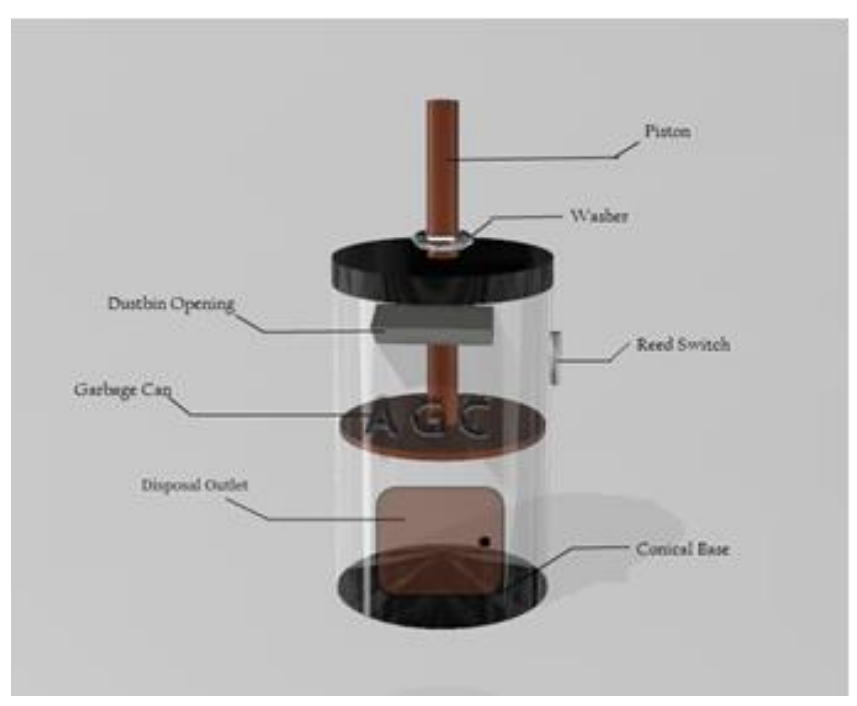

Fig.1. The Front View of Automated Garbage Compressor(self-designed)

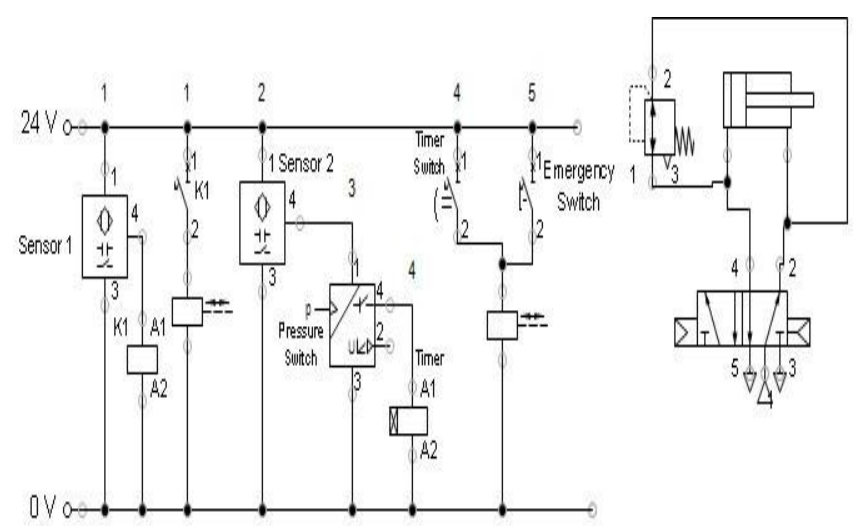

Fig. 2. AGC electro-pneumatic circuit on FluidSim

\section{Mechanism:}

The circuit of AGC was developed in the Simulation Lab of Manipal Institute of Technology, Manipal [7]. The circuit will receive a signal when the reed switch, located on the dustbin, senses the position of the garbage. That is, when the garbage in the dustbin is filled to the brim, the sensor will get activated and signal the piston to move to the forward end position. Consequently, the piston compresses the garbage up till the bottom most point of the bin. It does so, for exactly 30 seconds and when the time is up, the timer switch becomes normally open. Hence, the piston automatically returns to its initial position. AGC can be called a convenient asset to the Indian Railways as the only human labour it requires is to dispose of the garbage through the disposal outlet shown in Fig.1.

\section{Safety Measures}

The mechanism is simple but careful thought has been put into its formulation. For instance, if due to any technical difficulty, the AGC is going out of control or simply not performing to its full potential, any passenger or staff can press the emergency stop push button. It will ensure immediate break in the circuit and the mechanism will cease.

Another significant design consideration was to make a long pocket like entry to throw the garbage instead of the regular hole shaped one. This ensures absolutely no hand contact while depositing garbage which protects the passenger/staff from any injury which may be sustained if the piston is reciprocating. This type of structure also helps the garbage travel smoothly without sticking to the sides. These minor design considerations lead to a great deal of difference pragmatically and make AGC more user friendly.

\section{E. Force Analysis}

Force analysis refers to the calculation of the magnitude of force which will be applied on the garbage during forward and return motion. By calculating the area of the piston and the piston rod and keeping the pressure constant, the maximum 
force was determined. This of course, is an ideal case. The empirical value of force may differ from the theoretical one due to the losses incurred by the mechanism. For example, with time, the piston will wear and tear which will affect the value of the force. Also, frictional losses, heat loss and even fluctuation in pressure will change the magnitude of force. But, since it is nearly impossible to account for all the losses, it is feasible to mention the maximum force and then practically assume the effective value.

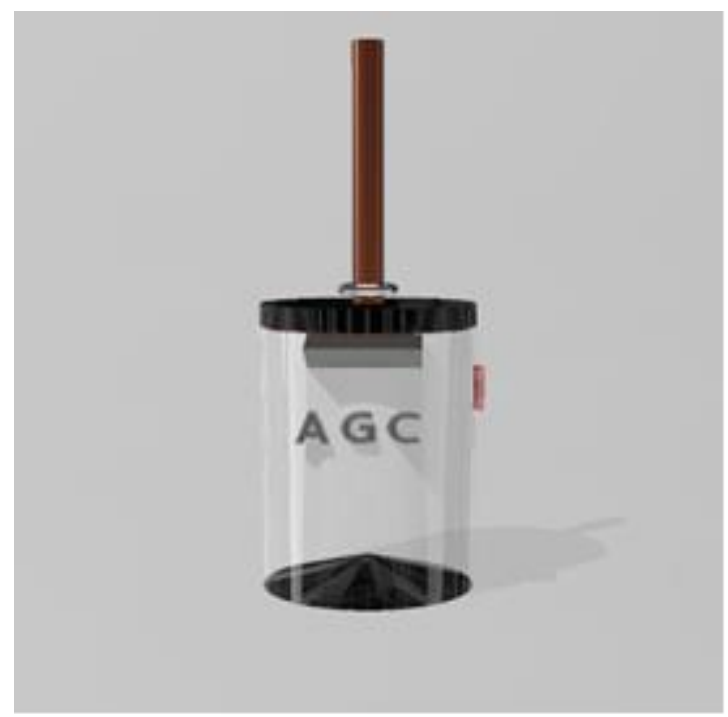

Fig. 3(a). The Initial Position of the Piston

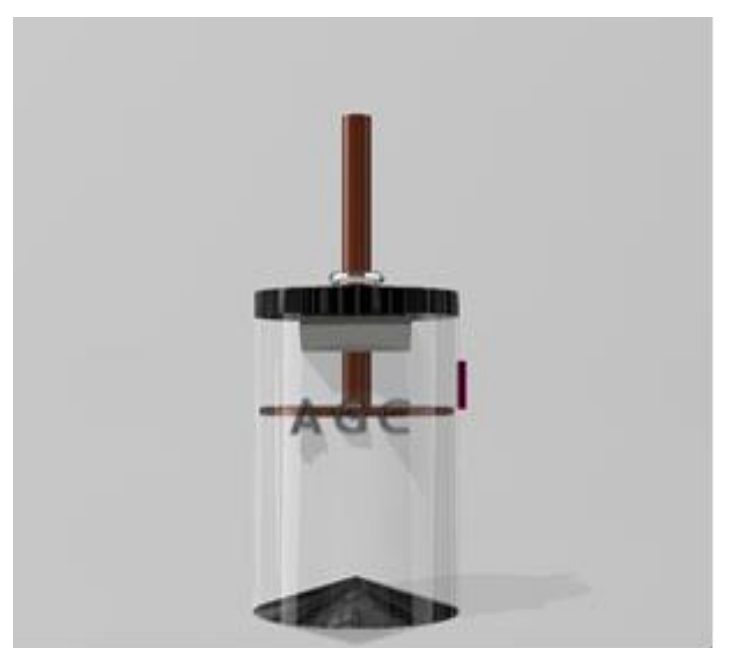

Fig. 3(b). The sensor blinks red when it gets actuated by the presence of garbage. Thus, the piston moves to the forward end position.

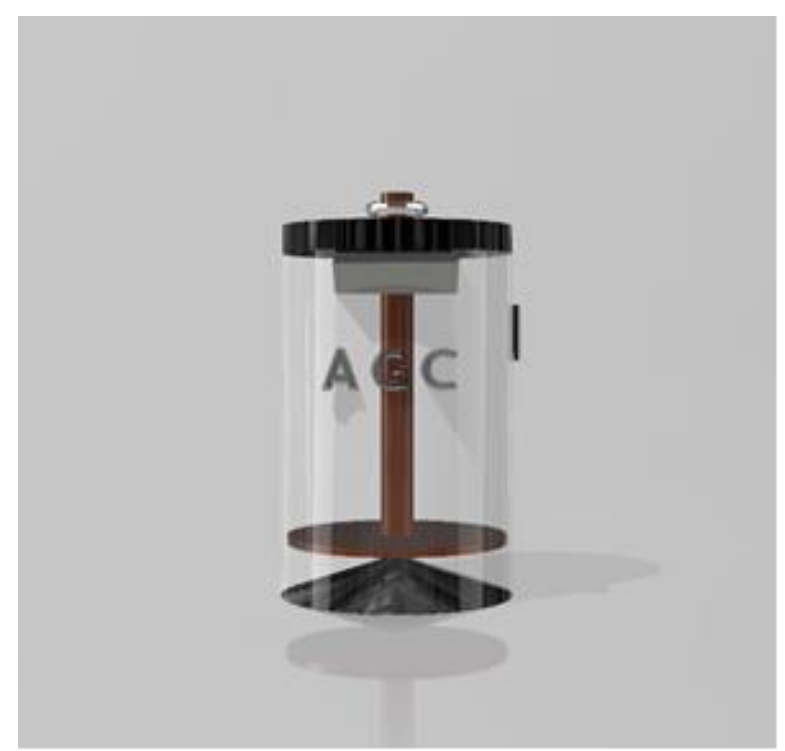

Fig. 3(c). The Piston compresses the garbage for 30 seconds and the sensor resets, retracting the piston.

\section{F. Material Analysis}

According to [5], yield strength of Aluminium 6061 is 310 $\mathrm{MPa}$. This means that beyond $310 \mathrm{MPa}$, the strain in the material becomes permanent or in other words the deformation is no longer elastic but has incurred

irreversible distortion [5, p.3]. This information is particularly useful to the manufacturer as it will assist him in determining the optimum weight of the garbage can and the piston rod. The material of the piston and the piston rod is sheet metal whose yield strength is approximately.

Why were these particular materials selected for this project?

Aluminium 6061 is corrosion resistance, comparatively stronger, has good machinability and can be found easily [8]. The material of the piston and the rod is chosen as grade 3003 H-14 sheet metal [6], because it has a low cost, high strength, good welding abilities and is resistant to corrosion [8]. These materials were the optimum choice for the project as they provide the right balance between strength and cost.

\section{RESULT}

\section{Calculations}

To provide a practical implication of the theory discussed above, the power consumed by the garbage can in watt and calculation of force applied by the piston while compression and return in newton, is imperative.

Area of the piston and the piston rod is calculated using the formulae shown in Table 1. The force during compression is conveniently calculated using the relation Force = Pressure/Area. 
The formulae shown Table $\mathbf{1}$ are taken from the book 'Pneumatic Controls' by Joji P. [9]

Table 1: Force Applied On the Piston and The Power Produced

\begin{tabular}{|c|c|}
\hline Equations & Theoretical Results \\
\hline $\begin{array}{l}1 . \mathrm{F}_{\mathrm{EXT}}=\mathrm{P} \times \mathrm{A}_{\mathrm{p}} \\
\mathrm{A}_{\mathrm{P}}=\left(\boldsymbol{\pi} \mathrm{D}_{\mathrm{p}}^{2} / 4\right)\end{array}$ & $\mathbf{5 6 . 6 7} \mathbf{~} \mathbf{N}$ \\
\hline $\begin{array}{c}2 . \mathrm{F}_{\mathrm{RET}}=\mathrm{P} \times\left(\mathrm{A}_{\mathrm{p}}-\mathrm{A}_{\mathrm{r}}\right) \\
\mathrm{A}_{\mathrm{r}}=\left(\boldsymbol{\pi} \mathrm{D}_{\mathrm{r}}^{2} / 4\right)\end{array}$ & $\mathbf{5 6 . 6 5} \mathbf{~ k N}$ \\
\hline 3.Power $=\mathrm{F}_{\mathrm{EXT}} \times \mathrm{V}_{\mathrm{EXT}}$ & $\mathbf{1 4 . 1 1} \mathbf{~ W}$ \\
\hline
\end{tabular}

Where,

1. FEX is the force applied by the piston during compression.

2. $\mathrm{F}_{\mathrm{RET}}$ is the force applied during the return of the piston.

3. $\mathrm{A}_{\mathrm{p}}$ is the area of the piston in $\mathrm{cm}^{2}$.

4. $\mathrm{A}_{\mathrm{r}}$ is the area of the piston rod in $\mathrm{cm}^{2}$.

5. $\mathrm{V}_{\text {EXT }}$ is the velocity of the piston during compression.

\section{DISCUSSION}

The Automatic Garbage Compressor cogently reinstates the principle of automation with the aid of Control Systems, concurrent to its eclectic real-time application. AGC promises a reliable and novel method of waste disposal in trains. It can be compliant towards the needs of the people and ensure a safe and hygienic environment for garbage disposal.

The previous research conducted by various authors, strongly advocates the need for AGC in railway coaches. It can be displayed conspicuously beside the wash basin or adjacent to the toilet wherever there is a convenient power source. It does not need a lot of maintenance or human intervention and will eliminate the risk of increasing pollution as it will remain covered at all times. As for the number of dustbins in each coach, AGC has a volume of 300 litres which is 2.5 times the average household dustbin and a compaction ratio of $3: 1$ which will easily accommodate the garbage of almost all the passengers in the coach. It has been carefully designed and keeps in mind the safety requirements of the people travelling in the train.

If implemented, AGC can prove to be a valuable asset for the Indian Railways. It will ensure a healthy human to machine interaction, minimise labour and thus improve productivity, bring about technological advancement and most importantly, it will give room to more innovation in the field of automation.

\section{CONCLUSION}

To conclude the paper, it is only rational to discuss a few shortcomings of the Automatic Garbage Compressor. Firstly, as mentioned earlier, AGC reduces human intervention considerably which can be a boon or a bane. It definitely reduces working hours but might also result in unemployment in some cases. However, due to modern developments in the field of Automation, employment opportunities might increase. Secondly, if AGC is duly approved and implemented in trains, the general public including the commuters and the staff members have to be open to the inclusion of new technologies. They should be willing to adapt to this rather friendly invasion and approach it with a modern mind-set. Thirdly, It might prove to be beneficial to install more than two units of AGC in order to reap higher profits. Lastly, this paper does not mention the actual power consumption of the AGC. However, power has been calculated theoretically, but its effect on the electricity cost incurred by the Railways has not been analysed.

In spite of all the limitations, AGC emphasises on the fact that it is a much needed inclusion to the current garbage disposal system employed in trains.

The future scope of the AGC can be anticipated once it is launched as a successful prototype. If the AGC proves to be ubiquitous, it can accrue social and economic benefit to the people and the society.

\section{ACKNOWLEDGEMENT}

We would like to extend a heartfelt gratitude to Mr. Padmaraj N.H. (Assistant Professor - Senior Scale) who gave shape to this project. He mentored us diligently and offered his expertise on the subject of Electro pneumatics.

This project would be incomplete without the help of $\mathrm{Mr}$ Chethan K. (Assistant Professor - Senior Scale) who guided us with the fabrication of the dustbin and helped us analyse the materials on the basis of yield strength, tensile strength and corrosion resistance.

We would also like to thank Manipal Academy of Higher Education (MAHE) for providing us with the equipment and the technology required to complete this project. Without these opportunities, our project would merely be an intangible vision.

\section{REFERENCES}

1. The Economic Times, (2017). "1.54 million people work for Indian Railways" in 10 facts we bet you didn't know about Indian Railways, India. https://economictimes.indiatimes.com/infrastructure/10 
-facts-we-bet-you-didnt-know-about-indian-railways/154-million-people-work-for-indianrailways/slideshow/57017992.cms

2. Ranjan. R, T. Rakesh, and Nair. V. Harish. (2016). "Indian trains are clean; tracks are dirty: Rajdhani staff found throwing trash on the tracks." India Today. https://www.indiatoday.in/mail-today/story/indiantrains-are- clean-tracks-are-dirty-rajdhani-stafffound-throwing-trash-on-the- tracks-15307-2 016-0621.

3. The Economic Times, (2019). "India rises 4 places to 44th rank in world digital competitiveness rankings",India.

https://economictimes.indiatimes.com/tech/internet/indi a-rises-4-places-to-44th-rank-in-world-digitalcompetitiveness rankings/articleshow/71312837.cms?from $=\mathrm{mdr}$

4. Standex Electronic, "Operate Time" in Reed Switch Electronics, https://standexelectronics.com/wpcontent/uploads/Parameters_of_Reed_Switch1.pdf

5. Azom. A, (2012). "Aluminum / Aluminum 6061 Alloy(UNSA96061)." https://www.azom.com/article.aspx?ArticleID=6636

6. Aalco. D, (2012). "Aluminum Alloy- Commercial Alloy- 3003 'O' Sheet".

7. University, Manipal. NA. Research MIT Manipal. NA: MIT Manipal. https://manipal.edu/mit/research.html

8. n.d.Alcoa.A,(2012).“Aluminum”https://www.alcoa.com /global/en/what-we-do/aluminum/.

9. P, Joji. (2008). "Pneumatic Control." N.p.: John Wiley $\&$ Sons.

10. Gawade. P. P.,G. Jadhav. P, Ingale. S.B., Patil. A.B., Patil. R.R., and Ingale. S.S. (2017). "Review Paper on Solar Trash Powered Compactor bin." International Advanced Research Journal in Science, Engineering and Technology 4, no. 11 (November): 4.

11. Vroom, B. Charles, Bentil John and Eshun David n.d. (2016) "Design of a Solid Waste Compactor." International Journal of Scientific Research and Innovative Technology 3(7): 9

12. Gawande, Abhishek. (2018). "Analyzing the Behavioral Pattern of Indian Railways Passengers with regards to Disposal of Waste." International Journal of Research - Granthaalayah 6, no. 4 (April): 6. 10.5281/zenodo.1242615. G.O. Young, "Synthetic structure of Industrial Plastics (Book Style with paper title and editor)," in Plastics, $2^{\text {nd }}$ ed. Vol. 3, J. Peters, Ed. New York: McGraw Hill, 1964, pp. 15-64. 